\title{
Retraction
}

\section{Retracted: Quadrupole Excitation in Tunnel Splitting Oscillation in Nanoparticle $\mathbf{M n}_{12}$}

\section{Advances in Condensed Matter Physics}

Received 11 April 2015; Accepted 11 April 2015

Copyright (C) 2015 Advances in Condensed Matter Physics. This is an open access article distributed under the Creative Commons Attribution License, which permits unrestricted use, distribution, and reproduction in any medium, provided the original work is properly cited.

The paper titled "Quadrupole Excitation in Tunnel Splitting Oscillation in Nanoparticle $\mathrm{Mn}_{12}$ " [1], published in Advances in Condensed Matter Physics, has been retracted as it is found to contain a substantial amount of material, without referencing, from the paper "Ground State Tunnel Splitting in $\mathrm{Mn}_{12}$ Acetate, undergraduate Senior Honors Thesis (Amherst College)," Micheal Foss-Feig, 2006.

\section{References}

[1] Y. Yousefi and K. K. Muminov, "Quadrupole excitation in tunnel splitting oscillation in nanoparticle," Advances in Condensed Matter Physics, vol. 2012, Article ID 530765, 4 pages, 2012. 